\title{
A Study of Sedimentation at the River Estuary on the Change of Reservoir Storage
}

\author{
Iskahar ${ }^{1, *}$, Suripin $^{2}$, and Isdiyana ${ }^{3}$ \\ ${ }^{1}$ Departement of Civil Engineering, Engineering Faculty, University Muhammadiyah Purwokerto, Purwokerto - Indonesia \\ ${ }^{1}$ Doctoral Student of Civil Engineering, Enginering Faculty, Diponegoro University, Semarang - Indonesia \\ ${ }^{2}$ Department of Civil Engineering, Diponegoro Univers ity, Semarang - Indonesia \\ ${ }^{3}$ Center River, Center of Research and Development Water Resources, Surakarta - Indonesia
}

\begin{abstract}
Estuary of the river that leads to the reservoir has characteristics include: relatively flat, there is a change in the increase of wet cross-sectional area and backwater. The backwater will cause the flow velocity to be reduced, so that the grains of sediment with a certain diameter carried by the flow will settle in the estuary of the river. The purpose of this research is to know the distribution and sedimentation pattern at the river estuary that leads to the reservoir with the change of water level in the reservoir storage, so the solution can be found to remove / reduce sediment before entering the reservoir. The method used is the experimental, by making the physical model of the river estuary leading to the reservoir. This study expects a solution to reduce sedimentation, so that sedimentation can be removed / minimized before entering the reservoir. This research tries to apply bypass channel to reduce the sedimentation at the river estuary. Bypass channels can be applied to overcome sedimentation at the river estuary, but in order for the sediment to be removed optimally, it is necessary to modify the mouth of bypass channel and channel angle.
\end{abstract}

\section{Introduction}

The sedimentation process and pattern of the river mouth leading to the reservoir is influenced by the basic sediment and river currents. The estuary of the river that leads to the reservoir has characteristics such as: relative ramps, there is a change in the increase of the wetland area, the backwater due to the water level of the reservoir storage, causing the flow velocity to decrease. This sediment reduces the channel's inflow capacity, which will finally affect the distribution and sedimentation pattern of the reservoir. Sedimentation in reservoirs will be result in decrease in reservoir storage capacity and functional life of reservoir and decrease of water quality of reservoir that will affect the performance and operation of reservoir. [1]

The purpose and objective of this research is to know the distribution and sedimentation pattern at the river estuary to the reservoir with the change of water level in the reservoir storage, so that solution or alternative can be found to reduce / remove sediment from the estuary of the river. In the experiment try to apply bypass channel to reduce sedimentation at the river estuary.

\section{Literature Review}

\subsection{Sediment Dynamics on the Reservoir delta}

Sediments in the delta area at the highest water level of the reservoir can cause gradation (deposition) upstream of the reservoir. This sedimentation reduces the channel's inflow capacity. Delta deposits are also the most visible part of the reservoir sedimentation. Reservoir deltas have the following basic characteristics [2]:

a) There is an abrupt change between the slope of the topset and foreset deposits.

b) Sediment particles on the topset bed are coarser than on the foreset beds, and there is an abrupt change in the particle diameter between the topset and foreset deposits.

c) The elevation of the transition zone from the topset to the foresets bed depends on the reservoir operating rule and pool elevation.

In deep reservoirs which have been operated at different levels, distinct deltas may be formed at different water levels. Reservoir deltas always grow in the downstream direction, and in some cases their vertical and upstream growth may also be significant. Because the upstream area of the reservoir is shallow and has little storage 
capacity the longitudinal growth of the delta may initially be very rapid. As the delta progresses downstream into deeper and wider portions of the reservoir, its rate of longitudinal growth slows.

As the delta advances downstream, the topset and foreset deposits prograde over previously deposited bottomset beds of finer sediments. This process can create alternating lenses of coarse and fine material as large events deliver coarse material deep into the impoundment, which may be subsequently overlaid by finer material. In general, fully penetrating cores in an extensively sedimented reservoir will reveal the finest sediment at the bottom, coarsening until the surface level is reached.

Sedimentation patterns reflect transport processes in reservoirs and as information on sediment delivery and distribution processes, so that predictable types of service disruptions and possible remedial strategies can be predicted. Sedimentation patterns in each reservoir will vary, depending on hydrological conditions, reservoir pond geometry, inflow discharge and sediment grain size characteristics and reservoir operations. Bed load and coarse fraction of the suspended load will soon settle to form the delta deposit at the end of the reservoir, while the fine sediment with a lower settling velocity will be transported deeper into the reservoir (see Figure $1)$.

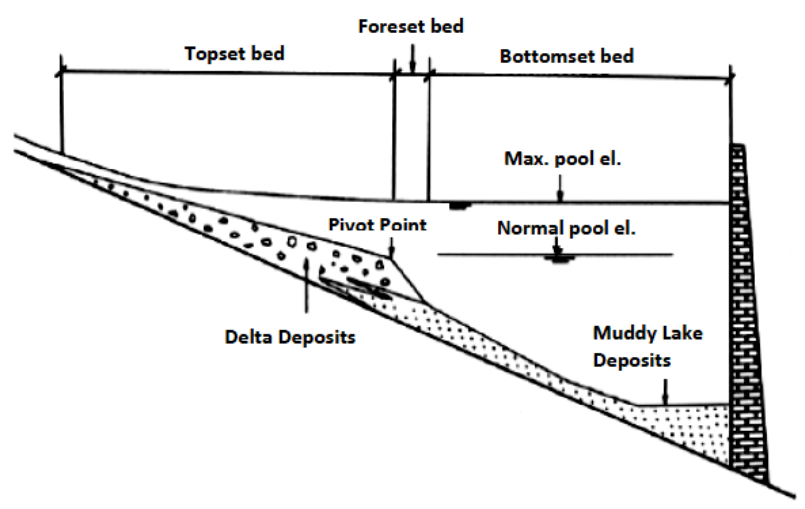

Fig. 1. Generalized depositional zones in a reservoir [2].

The longitudinal sedimentation zone in the reservoir can be divided into three main zones as follows [2]:

a. Topset bed; Composed of sediment material with larger grain size (coarse). The sediment is formed upstream to the end of the backwater, which forms a delta downstream to the end of the transport of the base material in the reservoir.

b. Foreset bed; Is a transitional part from the base of the top to the bottom of the base, starting from the forward delta into the reservoir. The difference is with the topset bed on increasing the slope and decreasing grain size.

c. Bottomset bed; Composed of fine sediment, formed from the base of the transitional portion toward the dam. This precipitate is formed because the sedimentary material is carried by turbidity or nonstratified flow (see Figure 1).
The presence of inflow from tributary, Decrease of reservoir water level, base landslides and extreme floods will cause the rough material to be transported to the normally deposited fine material zone, so that sedimentation or local variations will occur on the grain size of the sediment.

\subsection{Initial sediment motion}

The beginning of the Movement is important in the study of sediment transport, channel degradation, and stable channel design. Due to the stochastic nature of the sediment movement along the alluvial basis, it is difficult to define exactly whether the sediment particle flow conditions will begin to move. On channels with uniform grained sand material, which flows with certain discharges, the basic particles of the channel will surely experience a hydrodynamic force.

As the velocity and flow rates increase, the hydrodynamic forces that arise will increase in size, so that the particles can not survive and will begin to drift, where these are the so-called critical conditions or the beginning of movement. The force acting on a round sediment particle at the bottom of the open channel, which should be considered is the drag force $\mathrm{FD}_{\mathrm{D}}$, the lift force $F_{L}$, the submerged weight of Ws and the resistance force FR. [1] (See Figure 2)

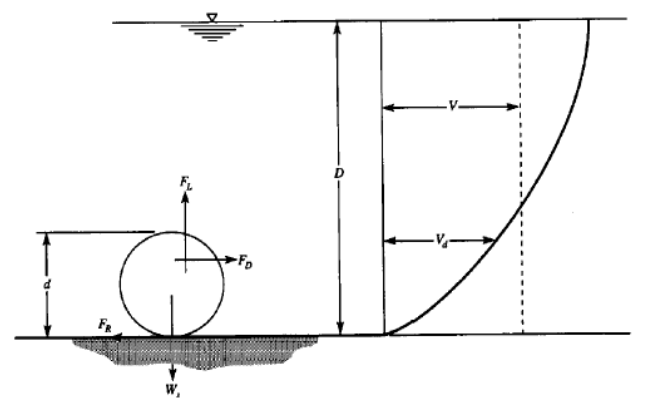

Fig. 2. The diagram of a force acting on sediment particles in an open channel [1].

A sediment particle is at a state of incipient motion when one of the following conditions is satisfied:

$$
F_{L}=W_{s} \text { or } F_{D}=F_{R} \text { or } M_{o}=M_{R}
$$

where :

$$
\begin{array}{ll}
\mathrm{F}_{\mathrm{D}}=\text { drag force, } & \mathrm{F}_{\mathrm{R}}=\text { resistence force } \\
\mathrm{F}_{\mathrm{L}}=\text { lift force, } & \mathrm{M}_{\mathrm{o}}=\text { overturning moment } \\
\mathrm{W}_{\mathrm{s}}=\text { submerged weight } & \text { due to } \mathrm{F}_{\mathrm{D}} \text { and } \mathrm{F}_{\mathrm{L}}, \\
& \mathrm{M}_{\mathrm{R}}=\text { resisting moment } \\
& \text { due to } \mathrm{F}_{\mathrm{L}} \text { and } \mathrm{W}_{\mathrm{s}}
\end{array}
$$

Most incipient motion criteria are derived from either a shear stress or a velocity approach. 


\subsection{Critical Shear Stress}

The results of research conducted by Shield on a flat base were the most widely used to estimate the critical condition of the initial movement of a particle. In the study the material is not uniform used size $\mathrm{D}_{50}$. Shield in his study found a relationship between critical drag force $\left(\psi_{\mathrm{c}}\right)$, critical shear stress $\left(\tau_{\mathrm{oc}}\right)$, and critical shear velocity $\left(\mathrm{U}^{*} \mathrm{c}\right)$, as follows [3]:

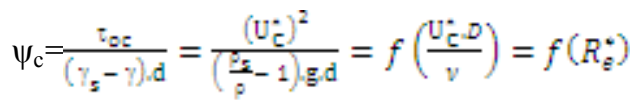

In the above formula it is shown that the factors affecting the grain motion are shear stress, shear velocity, water mass densities of fluid and sediment, particle diameter, kinematic viscosity number and gravity. The Shield has depicted a graph showing a silent particle and begins to move (see Figure 3).

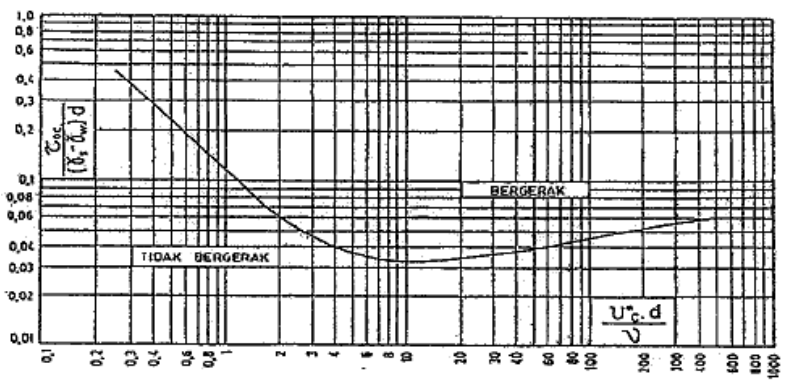

Fig. 3. Shield Diagram The Relation between Critical Shear Stress to Reynolds Numbers [3]

\subsection{Sediment Control Strategy}

Some opinions on strategies that can be done to control sediment according to some experts are as follows:

- According to Auel and Boes, some measures that can be taken to control sedimentation are by reducing sediment yields, sediment routing, and sediment removal, as shown in Figure 4. [4]

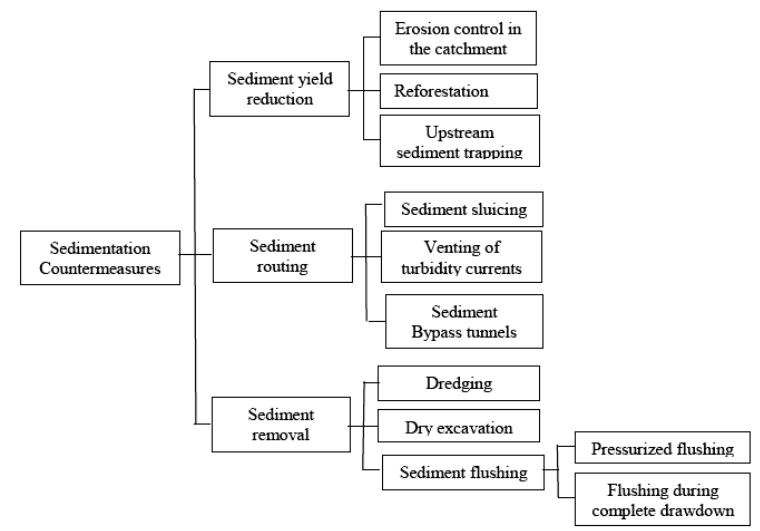

Fig. 4. Sedimentation control measures [4]

- According to Morris and Fan, to control sedimentation of the reservoir, there are several methods: [2]:

a. Minimize the entry of sediments into reservoirs by means of watershed conservation, constructing sediments (check dam) or with vegetation screen, bypass channels to degrade flow with high sediment concentrations in order not to enter the reservoir.

b. Minimize the occurrence of sediment deposition in the reservoir, by removing the sediment from the reservoir before sediment settles.

c. Removing sediment that has been settled in the reservoir, with flushing method and dredging

d. Replacing lost storage capacity by raising a dam or constructing a new reservoir.

- According to Palmieri, the methods that can be used for handling sedimentation reservoirs are: [5]

a. Reduce sediment inflow with watershed management, upstream control structures, bypass Reservoirs and off channel storage channels.

b. Regulates sediment in reservoirs with operating rules and tactical dredging.

c. Removing the sediment from the reservoir with flushing, sluicing, density current venting and mechanical dredging.

d. Restore lost storage capacity by raising high dams and constructing new dams.

e. Dam decommissioning

- According to Yang, the capacity of the lost reservoir can be restored by flushing, dredging, sluicing and siphoning. Flushing is more effective when emptying, or with lower outlet having sufficient capacity. Dredging is an expensive method for restoring reservoir capacity, done when flushing is ineffective, and bypass sediments are not possible. Siphoning is a fairly effective method for removing sediment from small reservoirs. [6]

- According to Liu et al. to control reservoir sedimentation used different methods such as bypassing, dredging, flushing, sluicing and retaining sediment upstream. To obtain maximum results are usually used a combination of the above methods. [7]

\section{Research Methods}

The method used in this research is the experimental method, with the physical model of the river estuary that goes to the reservoir, conducted in the field laboratory of "Balai Sungai Surakarta".

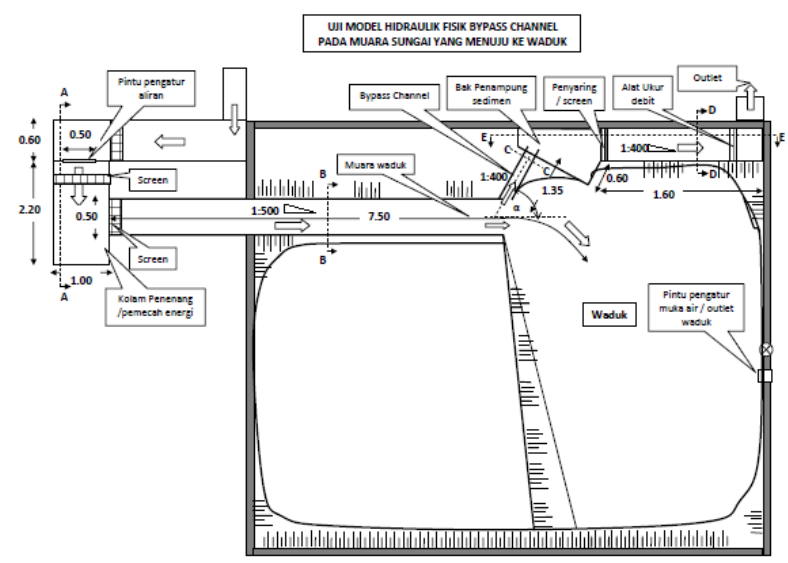

Fig. 5. Hydraulic model layout estuary leading to the reservo ir with a bypass channel 


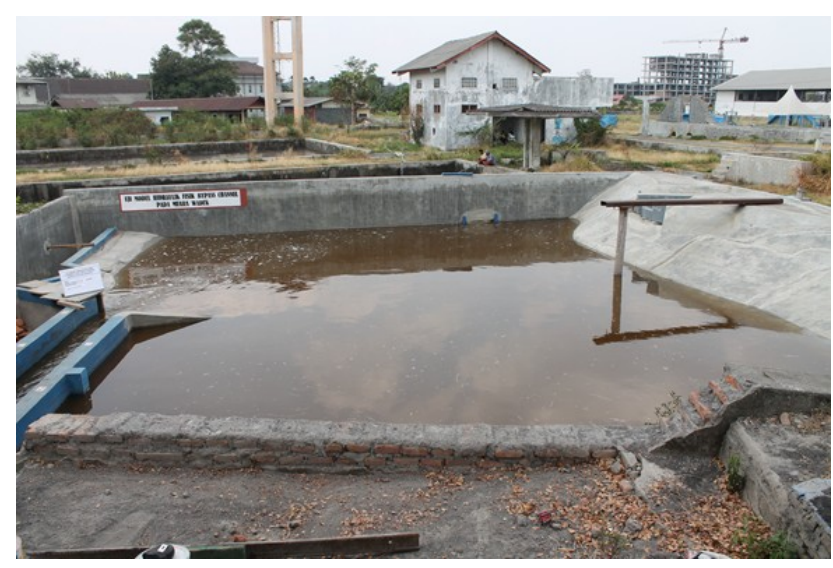

Fig. 6. Photo of Hydraulic model layout estuary leading to the reservoir with a bypass channel

In this study, it consists of two scenarios / series of tests, that is :

- Series 0 (Original)

To determine the natural behavior of sediments on estuary river that to reservoir, at an elevation of Low Water Level (LWL), Medium Water Level (MWL) and High Water Level (HWL), with variations of river flow discharge of $8 \mathrm{lt} / \mathrm{s}, 13 \mathrm{lt} / \mathrm{s}$ and $18 \mathrm{Lt} / \mathrm{s}$.

- Series 1 (with bypass channel)

To determine the movement of sediments on estuary river that to reservoir and the weight of the sediments coming out through the bypass channel, at an elevation of Low Water Level (LWL), Medium Water Level (MWL) and High Water Level (HWL), with variations of river flow discharge of $8 \mathrm{lt} / \mathrm{s}, 13 \mathrm{lt} / \mathrm{s}$ and $18 \mathrm{Lt} / \mathrm{s}$.

Observations or measurements are: flow velocity, flow depth, river flow discharge, outflow bypass channel, flow pattern, movement pattern and sediment contour after sediment flushing at the river estuary leading to the reservoir and the weight of sediment entering the reservoir and sediment out through the bypass channel.

Storage elevation on the medium water level (MWL) is the height of the reservoir water level parallel to the base estuary of the river mouth. Whereas the elevation of the reservoir at low water level (LWL) is set $1 \mathrm{~cm}$ below the MWL and the elevation of the reservoir on the high water level (HWL) is set $1 \mathrm{~cm}$ above the MWL.

\section{Results and Discussion}

\subsection{Flow Patterns}

The flow pattern in the series 0 and series 1 experiment is relatively similar, ie when the flow enters the stream the flow pattern forms a straight line along the river to the mouth of the river. Furthermore the flow enters to reservoir on a large area, the flow begins to twist to form the number eight and eventually breaks down after touching the wall of the reservoir boundary. As for series
1 when entering the branching flow will be divided, a small part of which goes into the bypass channel and mostly goes into the reservoir. The stream entering the bypass channel as it enters crashing the right wall then moves again crashing the left channel wall, so that the flow pattern line is tilted to the right and tilted to the left against the channel wall to the end of the channel bypass channel. (See Figure 7).

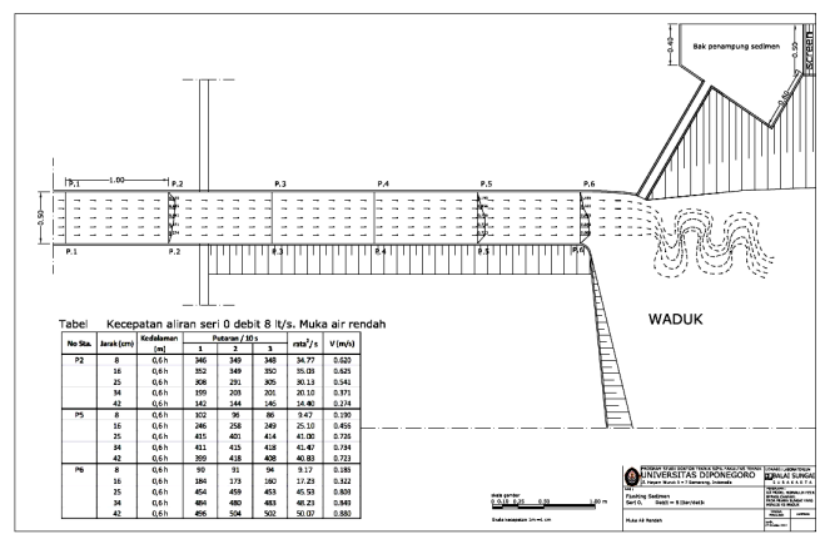

Figure 7. Experimental flow pattern series 0 (original / without bypass channel)

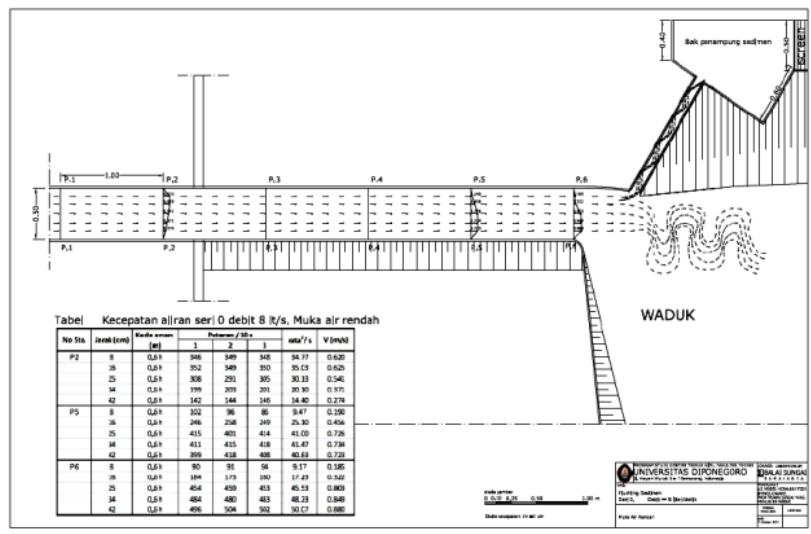

Figure 8. Experiment flow pattern series 1 (with bypass channel)

\subsection{Sediment Flushing}

In the sediment flushing experiments recorded data on the relationship between river flow discharge and outflow bypass channel (see table 1.). From the table it can be seen that the higher elevation of the reservoir storage, the outflow through the bypass channel will be greater. The greater river flow discharge, of course, the outflow through the bypass channel will be increase. So it can be estimated that with the higher elevation of the reservoir storage and the greater the river flow discharge, then the amount of sediment out through the bypass channel will be increase.

The sediment flushing experiment was carried out for 60 minutes, with three variations of discharge $(8 \mathrm{l} / \mathrm{s}, 13 \mathrm{l} / \mathrm{s}$ and $18 \mathrm{l} / \mathrm{s})$, three variations of sediment thickness $(5 \mathrm{~cm}$, $7 \mathrm{~cm}$ and $9 \mathrm{~cm}$ ) and three variations of reservoir storage 
(LWL, MWL and HWL). For the experimental results of sediment flushing can be seen in Table 2 .

Table 1. The relationship between river flow discharge and outflow bypass channel

\begin{tabular}{|c|c|c|c|}
\hline \multirow{2}{*}{$\begin{array}{c}\text { River Flow } \\
\text { Discharge } \\
\text { (l/s) }\end{array}$} & \multicolumn{3}{|c|}{ Outflow bypass channel (l/s) } \\
\cline { 2 - 4 } & LWL & MWL & HWL \\
$(\mathbf{l} / \mathbf{s})$ & $(\mathbf{l} / \mathbf{s})$ & $\mathbf{( 1 / s )}$ \\
\hline 8 & 0.438 & 0.465 & 0.802 \\
13 & 0.620 & 0.726 & 1.012 \\
18 & 1.012 & 1.105 & 1.526 \\
\hline
\end{tabular}

Table 2. Recapitulation of sediment flushing experiment in series 1

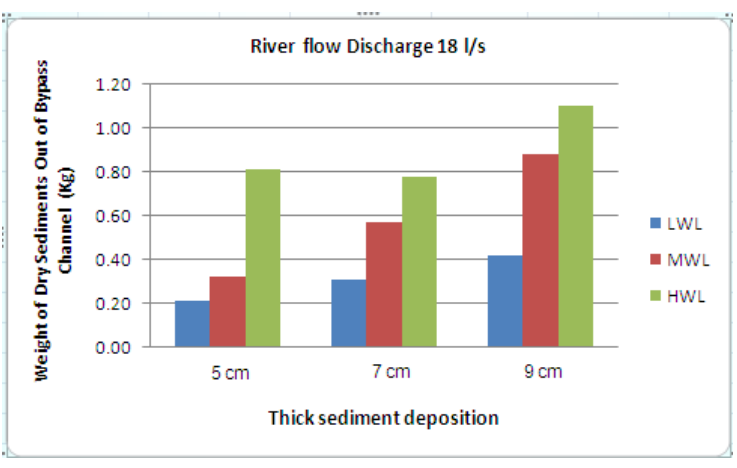

Fig. 11. Weight of Sediment Out bypass channel at $Q=18 \mathrm{l} / \mathrm{s}$

\begin{tabular}{|c|c|c|c|c|c|c|c|c|c|c|c|}
\hline \multirow[t]{2}{*}{$\begin{array}{l}\text { River flow } \\
\text { Discharge }\end{array}$} & \multirow{2}{*}{$\begin{array}{l}\text { Thick } \\
\text { sediment } \\
\text { deposition }\end{array}$} & \multirow{2}{*}{$\begin{array}{l}\text { Total } \\
\text { weight of } \\
\text { sediment }\end{array}$} & \multicolumn{3}{|c|}{$\begin{array}{l}\text { Weight of dry sediments } \\
\text { left in the river }\end{array}$} & \multicolumn{3}{|c|}{$\begin{array}{l}\text { Weight of dry sediments } \\
\text { out of bypass channel }\end{array}$} & \multicolumn{3}{|c|}{$\begin{array}{l}\text { Weight of dry sediments } \\
\text { left in the reservoir }\end{array}$} \\
\hline & & & LWL & MWL & HWL & LWL & MWL & HWL & LWL & MWL & HWL \\
\hline$(1 / \mathrm{s})$ & $(\mathrm{cm})$ & $(\mathrm{kg})$ & (kg) & $(\mathrm{kg})$ & (kg) & (kg) & (kg) & (kg) & (kg) & (kg) & (kg) \\
\hline 8 & 5 & 63.936 & 3.45 & 8.00 & 15.05 & 0.13 & 0.28 & 0.31 & 60.36 & 55.65 & 48.57 \\
\hline 8 & 7 & 85.248 & 3.30 & 7.30 & 17.50 & 0.26 & 0.51 & 0.72 & 81.69 & 77.44 & 67.02 \\
\hline 8 & 9 & 106.560 & 4.10 & 10.00 & 7.00 & 0.37 & 0.66 & 0.87 & 102.09 & 95.90 & 98.69 \\
\hline 13 & 5 & 63.936 & 0.18 & 1.67 & 11.80 & 0.15 & 0.30 & 0.50 & 63.61 & 61.97 & 51.64 \\
\hline 13 & 7 & 85.248 & 1.20 & 1.80 & 11.30 & 0.28 & 0.55 & 0.76 & 83.77 & 82.90 & 73.19 \\
\hline 13 & 9 & 106.560 & 2.20 & 3.10 & 10.50 & 0.38 & 0.76 & 0.97 & 103.99 & 102.70 & 95.09 \\
\hline 18 & 5 & 63.936 & 0.00 & 0.71 & 0.00 & 0.21 & 0.32 & 0.81 & 63.73 & 62.91 & 63.13 \\
\hline 18 & 7 & 85.248 & 0.00 & 0.20 & 2.40 & 0.31 & 0.57 & 0.78 & 84.94 & 84.48 & 82.07 \\
\hline 18 & 9 & 106.560 & 0.00 & 0.82 & 9.30 & 0.42 & 0.88 & 1.10 & 106.14 & 104.86 & 96.16 \\
\hline
\end{tabular}

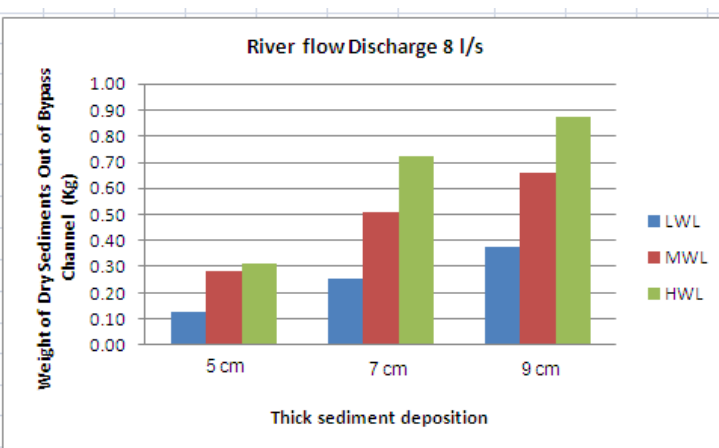

Fig. 9. Weight of Sediment Out bypass channel at $Q=81 / \mathrm{s}$

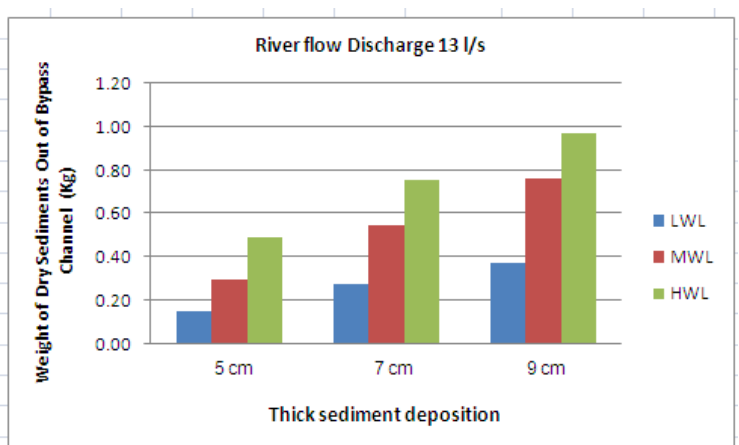

Fig. 10. Weight of Sediment Out bypass channel at $Q=13 \mathrm{l} / \mathrm{s}$
From the table and graph shows that the higher elevation of the reservoir storage, the sediment that goes into the reservoir decreases and the sediment out through the bypass channel increases. The greater the flow discharge in the river, the sediments entering the reservoirs and sediments out through the bypass channels are increasing. Likewise, with increasing sediment depth thickness, sediments entering reservoirs and sediments through the bypass channels are increasing. So to get more bypass channel outlet sediments, the elevation of the reservoir storage in HWL and with large river flow discharge.

For example the image of sediment contours after flushing for 60 minutes can be seen in Figure 11 (for series 0 ) and Figure 12 (for series 1 ). In this case the examples described are selected for flushing at $18 \mathrm{l} / \mathrm{s}$ flow discharge, and $9 \mathrm{~cm}$ of thick sediment deposition, as both are the largest discharge and largest thick deposits of the variations used in this study, in which the sediment contour image obtained, it is clear the difference between the reservoir storage LWL, MWL and HWL. 


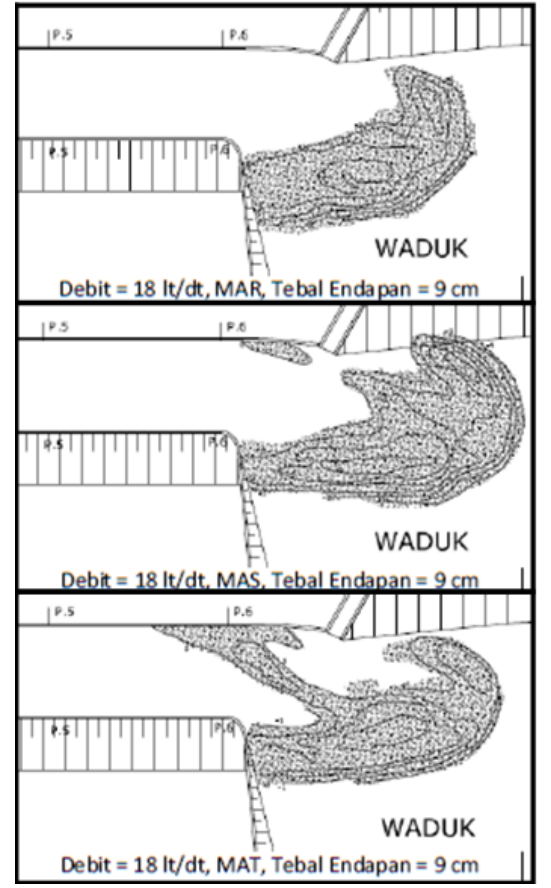

Fig. 12. Examples of contour images of sediments in the experimental series 0

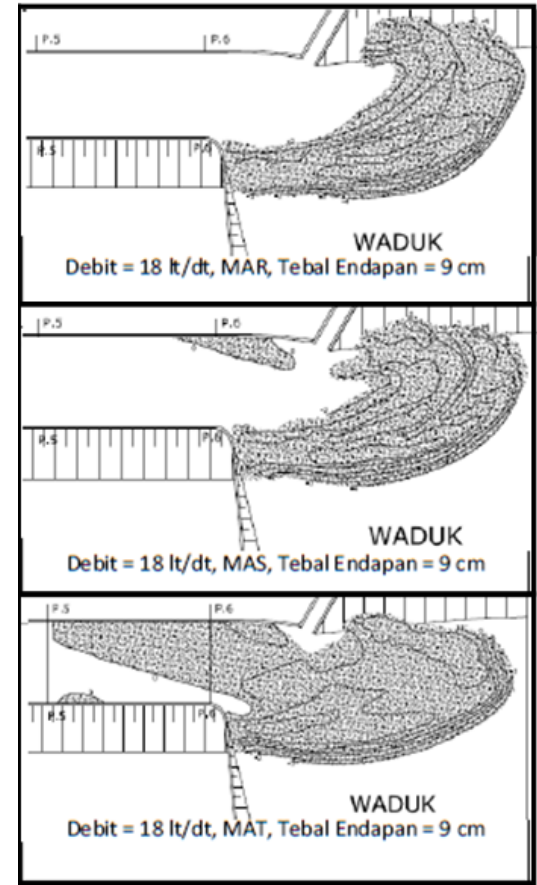

Fig. 13. Examples of contour images of sediments in the experimental series 1

In the series 0 experiment, at a flow discharge of $18 \mathrm{l} / \mathrm{s}$ with a sediment thickness of $9 \mathrm{~cm}$, the LWL showed that sediment deposits entirely entered the reservoir (nothing left in the river). In MWL it appears that most sediment deposits enter the reservoir and only a small amount of sediment is left in the river. Here it appears the effect of backwater has appeared, but not so strong. While the HWL seen sediment deposit that are still left in the river, this is because the influence of backwater reservoirs storage on HWL is strong enough.
In the series 1 experiment, at a flow discharge of $18 \mathrm{l} / \mathrm{s}$ with a $9 \mathrm{~cm}$ thick deposit, it appears that the sediment LWL entirely enters the reservoir (nothing left in the river) and only a few enter the bypass channel. In MWL it appears that most sediment deposits enter the reservoir, only a small amount of sediment is left in the river, and only a few enter the bypass channel. This shows that the effect of backwater reservoirs storage in MWL has emerged, but not yet so strong. In the HWL it appears that most sediment deposits enter the reservoir, the sediments left in the river are slightly higher, and those that enter the bypass channel are slightly increased. This shows that the effect of backwater reservoir storage on HWL is strong enough.

Thus, in order for the sediment that comes out more bypass channels, it is necessary to have a guidance structure in the form of submerge dike, to collect and direct the sediment into the bypass channel and the need to change the branching angle from $\alpha=60^{\circ}$ to $\alpha=45^{\circ}$ in order for more sediment to enter bypass channel. This is also supported by research conducted [8] which states that the maximum secondary flow stress occurs in the bend section with a transfer angle of $45^{\circ}$. In addition, the transfer from the stream to the bypass channel angle made stream line, so sediment will be easier to enter the bypass channel.

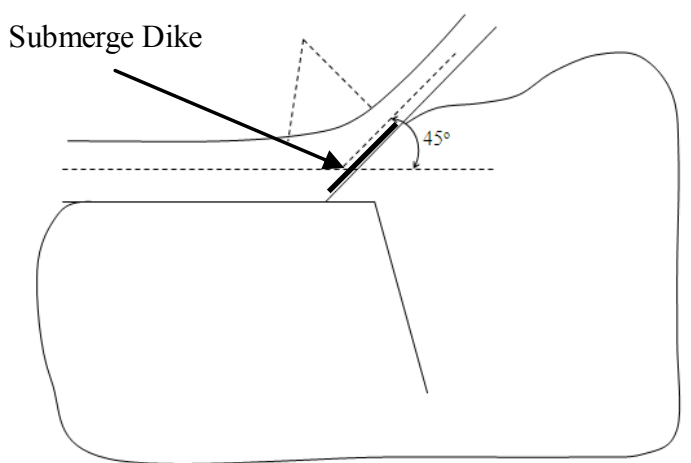

Fig. 14. Sketch of hydraulic model modification

\section{Conclusions and recommendations}

Some conclusions can be mentioned here related to sedimentation at the mouth of the river that leads to the reservoir, namely:

- In the sediment flushing experiment at the river estuary leading to the reservoir, the effect of reservoir backwater began to appear at the elevation of the MWL and the increasing backwater effect at the HWL elevation.

- The elevation of the reservoir storage strongly influences the sedimentation pattern occurring at the river estuary leading to the reservoir and also affects the amount of sediment in the river mouth that can be come out through the bypass channel.

- The experimental results show that the higher elevation of the reservoir storage, the sediment entering the reservoir decreases and the sediment that 
goes through the bypass channels is increasing. The greater the flow discharge in the river, the sediments entering the reservoirs and sediments come out through the bypass channels are increasing. Likewise, with increasing sediment depth thickness, sediments entering reservoirs and sediments come out through the bypass channels are increasing. So to get more bypass channel outlet sediments, the elevation of the reservoir storage in HWL and with large river flow discharge.

To get the sediment deposition out through the bypass channel more optimally, the author's suggestion is that additional series modifications are needed, that is by adding a submerge dike, as a structure for collecting and directing the sediment into the bypass channel and the need for change the branching angle from $\alpha=60^{\circ}$ to $\alpha=$ $45^{\circ}$ to allow more sediment into the bypass channel. In addition to the channel diversion from the stream to the bypass channel angle is made smooth or stream line, so sediment will be easier to enter the bypass channel.

\section{References}

1. 1 Anonymous, Reclamation Managing Water in the West-Erosion and Sedimentation Manual, , Bureau of Reclamation - US Department of the Interior, Denver, Colorado (2006).

2. 2. G.L. Morris, and J. Fan, Reservoir Sedimentation Handbook : Design and Management of Dams, Reservoirs, and Watersheds for Sustainable use, Electronic version ver 1.04, McGraw-Hill Company (2010)

3. 3 Yiniarti, Book sediment transport courses, Bandung (1999).

4. 4 Auel dan R. Boes, Sedimentation Reservoir of Alpine Reservoirs and Possible Counter Measures, Vienna (2011).

5. 5. E. H.Coker, R.H. Hotchkiss, and D.A. John, Journal of The American Water Resources Association. Vol 45, No. 4, pp. 815-827 (2009).

6. 6 C.T. Yang, Sediment Transport Theory and Practice, McGraw-Hill Company (1996).

7. 7 J. Liu, , S. Minami, H. Otsuki, , B. Liu and K. Ashida, J. Hydraulic Eng., Vol. 130 Number. 11, pp.1089- 1096 (2004).

8. 8 H. Montaseri, M. Ghodsian , M. Shafieefar, S.A.A. Salehi Neyshaboouri, and A.A. Dehghani, J. Agriculture Science .Nature Resources, Vol.15, Number 2 (2008). 